\title{
An Investigation of Sibu Express Boat Passenger Terminal Transportation risks
}

\author{
Lau, J. S. S ${ }^{1}$, Chan, R. A.B. ${ }^{2}$
}

\begin{abstract}
River transportation is essential in Sarawak as the roads are found difficult to be constructed due to difficult terrains, high construction cost for bridges and long construction period. Due to inaccessibility via road, river transportation is the only mean of transportation to rural area and the demand is increasing. On the other hand, the demands are also directly proportional to the occurrence of hazards or risks. Risk identification is a key step in risk management. This paper uses Sibu Express Boat Terminal as a background study and 5 points Likert score is used to rate likelihood and consequences for 36 risk factors. Risk ranking, Spearman rank correlation and sensitivity analysis were then applied for statistical data analyses. From the study, financial related risks ranked the highest and the policy and political risks ranked the lowest. Besides, the Spearman rank correlation method shows there is a relationship between likelihood and risk level. Likewise, there is a relationship between consequences and risk level as well. Results suggested that further research is required by increasing numbers of risk factors, risk groups as well as respondents.
\end{abstract}

Keywords: river transportation system, risk identification, risk management, risk level

\section{INTRODUCTION}

$\mathrm{R}$ AJANG River in Sarawak is the longest river and busiest water highway in Malaysia. The largest town in Rajang Basin, Sibu, is the gateway of the great Rajang River. It is also a commercial port for Rajang Basin due to its adjacent river system. River transportation in Sarawak is vital and it is currently the only infrastructure network in rural area especially Rajang tributaries where it is not accessible by road and air transportation [7]. Besides, Sarawak Rivers Board (SRB) and United Nations Development Programme (UNDP) had stated that rivers in Sarawak will be improved as a practicable and integral form of transport in rural area [1]. According to SRB and UNDP, there were 318 reported cases of fatalities in rivers of Sarawak since 2000 to 2006. Among the main reasons for the fatalities include inadequate navigational aids and signage, negligence and lack of proper safety training and awareness among boat captains as well as passengers. River transportation is crucial in rural area of Sarawak as the road network is found to be difficult to implement due to difficult terrains, high construction cost for bridges and long construction period. River system in Sarawak is much better than the road network since the rural areas and villages in Sarawak are still accessible by using river transportation. Because of the inaccessible of road vehicles, river transportation is the only mean of transportation and the demand is increasing. On the other hand, the demands are also directly proportional to the occurrence of hazards or risks.

Therefore, this paper has concentrated on the risk identification for river transportation system at Sarawak River focusing on Sibu Express Boat Terminal. Risk is product of probability of an event occurring and the consequences of its occurrence [3] - [7]. Through carry out of proper risk identification, various uncertain situations can be anticipated and resolved thus improving the current method of risk identification.

\section{METHODOLOGY}

The main respondents of this research are the engineers from private sectors as well as public sectors. All respondents are required to fill the survey questionnaire with 36 risk factors which were categorised into 6 risk groups. Each risk factor has its likelihood and consequences and it is scored by using Likert five scores. For likelihood, the score used as a grading standard for the occurrence of a risk factor with 5 (almost certain), 4 (likely), 3 (possible), 2 (unlikely), and 1 (rare). Likewise, the score is also used as a grading standard for the consequence or impact of a risk factor with 5 (catastrophic), 4 (major), 3 (moderate), 2 (minor), and 1 (insignificant) [9].

Therefore, the questionnaire was distributed and explained in detail for the respondents to fill in. The questionnaires were distributed by two forms which were paper survey and online survey. There were 49 sets of completed data retrieved from paper survey and the remaining was obtained through an online survey. There were also 10 sets of incomplete data retrieved.

\footnotetext{
${ }^{1}$ Lau, J.S.S. was with the Department of Civil Engineering, Faculty of Engineering, Universiti Malaysia Sarawak, 94300 Kota Samarahan, Sarawak, Malaysia

${ }^{2}$ Chan, R.A.B. is with the Department of Civil Engineering, Faculty of Engineering, Universiti Malaysia Sarawak, 94300 Kota Samarahan, Sarawak, Malaysia (email: acron@feng.unimas.my, ronaldrino@ hotmail.com )
} 
There are four measurement scales namely nominal scales, ordinal scale, interval scale, interval scale, and ratio scale. These four measurement scales can differentiate based on measurement data and frequency data. Nominal scale serves no true measurement. It provides a name or label for different objects and events and numbers used only for identification and classification. Ordinal scale has a number assigned and notified the ranking or rank ordering without showing the performance of each relative to another. Interval scale is each unit has assumed to be equal to each other unit on the scale. Interval scale has the categorising and ranking properties of the nominal and ordinal scales. It also has the property of having equal interval between the scores. Lastly, ratio scale has all the properties in addition to having a true zero [8]. The data were then analysed by retrieving the mean value for the risk level of each risk factor. Then, the Spearman rank correlation method is carried out and Spearman rank correlation coefficient, $\rho$ is calculated as formula stated below:

$$
p=1-\frac{6 \cdot \sum\left(x_{i}-w_{i}\right)^{2}}{n\left(n^{2}-1\right)}
$$

where $u_{i}$ and $v_{i}$ are the ranks of the $i$ th pair of $X$ and $Y$ variable [2]. Besides, the sensitivity analysis is carried out by plotting spider plot of likelihood versus risk level and spider plot of consequence versus risk level for each risk group.

\section{DATA ANALYSIS}

From retrieved questionnaires, only completed sets of data were used for statistical analyses. Therefore, 60 sets of data will be used to generate a risk level for each risk factor by using SPSS version 19.0. Then, the risk factors were ranked from the lowest to highest and shown in Table 1.0.

Table 1.0 Risk ranking

\begin{tabular}{|c|c|c|}
\hline Risk Factors & Risk Level & Rank \\
\hline Labour disputes and strikes & 7.78 & 1 \\
\hline Changes in laws and regulations/government policies & 8.17 & 2 \\
\hline Conventional design and construction method & 9.00 & 3 \\
\hline Insolvency of client & 9.38 & 4 \\
\hline Variation at managerial level & 9.97 & 5 \\
\hline Inexperienced designer & 10.18 & 6 \\
\hline Surface water/run-off & 10.45 & 7 \\
\hline Loss of human resources & 10.47 & 8 \\
\hline Expedition, lag, or changes in the priority level of project because of financial issues & 10.48 & 9 \\
\hline Undue political influence & 10.52 & 10 \\
\hline Inappropriate (over/under) design & 10.63 & 11 \\
\hline Variation orders because operational limitation & 10.68 & 12 \\
\hline Delay in auditing and payment of contractors provisional monthly statements & 10.78 & 13 \\
\hline Changes in material specification & 10.82 & 14 \\
\hline Loss or damage to machine/structure & 10.83 & 15 \\
\hline Accidents on site & 11.13 & 16 \\
\hline Errors in design drawings due to incomplete or defective design scope & 11.15 & 17 \\
\hline Prolonged rainfall & 11.18 & 18 \\
\hline Accidents on river transport/river structure & 11.27 & 19 \\
\hline Stipulation of specific codec and standards for river structures and ships/yards/vessels & 11.28 & 20 \\
\hline Delays in imparting work orders correctively & 11.30 & 21 \\
\hline Changes in ground specifications & 11.30 & 21 \\
\hline Inadequate design details and specifications & 11.32 & 23 \\
\hline Financial allocation more/less than cash flow balance & 11.42 & 24 \\
\hline Available funds from client for terminal building or ships/yards/vessels on time & 11.47 & 25 \\
\hline Market risk and recession & 11.57 & 26 \\
\hline Contractual relationship & 11.63 & 27 \\
\hline Landslides & 12.07 & 28 \\
\hline Damage to water resources & 12.07 & 28 \\
\hline Public safety as user of river structure & 12.08 & 30 \\
\hline Sedimentation and siltation & 12.10 & 31 \\
\hline Project extension of time due to changes & 12.23 & 32 \\
\hline Flooding & 12.53 & 33 \\
\hline Public safety as user of river transportation & 12.80 & 34 \\
\hline Price escalation on materials, equipments and labour costs & 13.02 & 35 \\
\hline Using poor quality material/inexperienced personnel due to financial issues & 13.13 & 36 \\
\hline
\end{tabular}

Besides, the Spearman rank correlation method was made to find the relationship between likelihood and risk level or and also relationship between consequences and risk level. Both tables for Spearman rank correlation were shown as Table 2.0 and Table 3.0 respectively. 
UNIMAS e-Journal of Civil Engineering: Volume 4, Issue 2

Furthermore, sensitivity analysis or known as graphical analysis also done to seek the relationship between the risk groups and the likelihood of the risk level as well as the relationship between the risk groups and the consequences of the risk level. The scatter plots were shown in Figure 1.0 and Figure 2.0 respectively.

Table 2.0 Spearman rank correlation between likelihoods and risk levels

\begin{tabular}{|c|c|c|c|c|c|}
\hline \multirow[b]{2}{*}{ Risk Factor } & \multicolumn{2}{|l|}{ Mean } & \multirow[b]{2}{*}{$\begin{array}{l}\text { Rank } \\
\text { of } \\
\text { likely- } \\
\text { hood }\end{array}$} & \multirow[b]{2}{*}{$\begin{array}{l}\text { Rank } \\
\text { of } \\
\text { Risk } \\
\text { Level } \\
\text { mean }\end{array}$} & \multirow{2}{*}{$\begin{array}{l}\text { Squared } \\
\text { of } \\
\text { difference } \\
\text { between } \\
\text { likelihood } \\
\text { and risk } \\
\text { level }\end{array}$} \\
\hline & $\begin{array}{l}\text { Likeli- } \\
\text { hood }\end{array}$ & $\begin{array}{l}\text { Risk } \\
\text { Level }\end{array}$ & & & \\
\hline Available funds from client for terminal building or ships/yards/vessels on time & 3.37 & 11.47 & 7 & 12 & 25.00 \\
\hline Insolvency of client & 2.82 & 9.38 & 34 & 33 & 1.00 \\
\hline Delay in auditing and payment of contractors provisional monthly statements & 3.28 & 10.78 & 17 & 24 & 49.00 \\
\hline Using poor quality material/inexperienced personnel due to financial issues & 3.42 & 13.13 & 4 & 1 & 9.00 \\
\hline Financial allocation more/less than the cash flow balance & 3.37 & 11.42 & 8 & 13 & 25.00 \\
\hline Market risk and recession & 3.32 & 11.57 & 13 & 11 & 4.00 \\
\hline Stipulation of specific codec and standards for river structures and ships/yards/vessels & 3.33 & 11.28 & 11.5 & 17 & 30.25 \\
\hline Errors in design drawings due to incomplete or defective design scope & 3.00 & 11.15 & 31 & 20 & 121.00 \\
\hline Conventional design and construction method & 3.12 & 9.00 & 24 & 34 & 100.00 \\
\hline Inexperienced designer & 2.85 & 10.18 & 33 & 31 & 4.00 \\
\hline Inappropriate (over/under) design & 2.92 & 10.63 & 32 & 26 & 36.00 \\
\hline Variation orders because operational limitation & 3.30 & 10.68 & 15.5 & 25 & 90.25 \\
\hline Delays in imparting work orders correctively & 3.27 & 11.30 & 18 & 15.5 & 6.25 \\
\hline Changes in ground specifications & 3.25 & 11.30 & 19.5 & 15.5 & 16.00 \\
\hline Inadequate design details and specifications & 3.25 & 11.32 & 19.5 & 14 & 30.25 \\
\hline Changes in material specification & 3.37 & 10.82 & 5.5 & 23 & 306.25 \\
\hline Project extension of time due to changes & 3.53 & 12.23 & 2 & 5 & 9.00 \\
\hline Price escalation on materials, equipment and labour costs & 3.55 & 13.02 & 1 & 2 & 1.00 \\
\hline Variation at managerial level & 3.05 & 9.97 & 28 & 32 & 16.00 \\
\hline Labour disputes and strikes & 2.50 & 7.78 & 36 & 36 & 0.00 \\
\hline Changes in laws and regulations/government policies & 2.60 & 8.17 & 35 & 35 & 0.00 \\
\hline Expedition, lag, or changes in the priority level of project because of financial issues & 3.12 & 10.48 & 23 & 28 & 25.00 \\
\hline Undue political influence & 3.08 & 10.52 & 25 & 27 & 4.00 \\
\hline Contractual relationship & 3.33 & 11.63 & 10 & 10 & 0.00 \\
\hline Flooding & 3.37 & 12.53 & 5.5 & 4 & 2.25 \\
\hline Landslides & 3.22 & 12.07 & 21.5 & 8.5 & 169.00 \\
\hline Damage to water resources & 3.30 & 12.07 & 15.5 & 8.5 & 49.00 \\
\hline Surface water/run-off & 3.32 & 10.45 & 14 & 30 & 256.00 \\
\hline Prolonged rainfall & 3.33 & 11.18 & 9 & 19 & 100.00 \\
\hline Sedimentation and siltation & 3.47 & 12.10 & 3 & 6 & 9.00 \\
\hline Public safety as user of river structure & 3.22 & 12.08 & 21.5 & 7 & 210.25 \\
\hline Public safety as user of river transportation & 3.33 & 12.80 & 11.5 & 3 & 72.25 \\
\hline Accidents on site & 3.07 & 11.13 & 26 & 21 & 25.00 \\
\hline Accidents on river transport/river structure & 3.03 & 11.27 & 29 & 18 & 121.00 \\
\hline Loss or damage to machine/structure & 3.05 & 10.83 & 27 & 22 & 25.00 \\
\hline Loss of human resources & 3.00 & 10.47 & 30 & 29 & 1.00 \\
\hline Total & & & & & 1948.00 \\
\hline Rank Order Correlation Coefficient & 0.750 & & & & \\
\hline
\end{tabular}


UNIMAS e-Journal of Civil Engineering: Volume 4, Issue 2

Table 3.0 Spearman rank correlation between consequences and risk levels

\begin{tabular}{|c|c|c|c|c|c|}
\hline Risk Factor & \multicolumn{2}{|l|}{ Mean } & $\begin{array}{l}\text { Rank } \\
\text { of } \\
\text { consequences }\end{array}$ & $\begin{array}{l}\text { Rank } \\
\text { of } \\
\text { Risk } \\
\text { Level }\end{array}$ & $\begin{array}{l}\text { Squared of } \\
\text { difference } \\
\text { between } \\
\text { consequences } \\
\text { and risk level }\end{array}$ \\
\hline $\begin{array}{l}\text { Available funds from a client for terminal building or } \\
\text { ships/yards/vessels on time }\end{array}$ & 3.28 & 11.47 & 27 & 12 & 225.00 \\
\hline Insolvency of client & 3.33 & 9.38 & 23 & 33 & 100.00 \\
\hline $\begin{array}{l}\text { Using poor quality material/inexperienced personnel due to } \\
\text { financial issues }\end{array}$ & 3.67 & 13.13 & 5 & 1 & 16.00 \\
\hline Financial allocation more/less than the cash flow balance & 3.33 & 11.42 & 22 & 13 & 81.00 \\
\hline Market risk and recession & 3.38 & 11.57 & 19 & 11 & 64.00 \\
\hline $\begin{array}{l}\text { Stipulation of specific codec and standards for river structures and } \\
\text { ships/yards/vessels }\end{array}$ & 3.32 & 11.28 & 24 & 17 & 49.00 \\
\hline Inexperienced designer & 3.40 & 10.18 & 16.5 & 31 & 210.25 \\
\hline Inappropriate (over/under) design & 3.48 & 10.63 & 11 & 26 & 225.00 \\
\hline Variation orders because operational limitation & 3.22 & 10.68 & 29 & 25 & 16.00 \\
\hline Delays in imparting work orders correctively & 3.40 & 11.30 & 16.5 & 15.5 & 1.00 \\
\hline Changes in ground specifications & 3.42 & 11.30 & 15 & 15.5 & 0.25 \\
\hline Inadequate design details and specifications & 3.35 & 11.32 & 21 & 14 & 49.00 \\
\hline Changes in material specification & 3.15 & 10.82 & 32 & 23 & 81.00 \\
\hline Project extension of time due to changes & 3.37 & 12.23 & 20 & 5 & 225.00 \\
\hline Price escalation on materials, equipment and labour costs & 3.55 & 13.02 & 9 & 2 & 49.00 \\
\hline Variation at managerial level & 3.20 & 9.97 & 30 & 32 & 4.00 \\
\hline Labour disputes and strikes & 2.98 & 7.78 & 35 & 36 & 1.00 \\
\hline Damage to water resources & 3.62 & 12.07 & 6 & 8.5 & 6.25 \\
\hline Surface water/run-off & 3.08 & 10.45 & 33 & 30 & 9.00 \\
\hline Prolonged rainfall & 3.28 & 11.18 & 26 & 19 & 49.00 \\
\hline Sedimentation and siltation & 3.43 & 12.10 & 13.5 & 6 & 56.25 \\
\hline Public safety as user of river structure & 3.62 & 12.08 & 8 & 7 & 1.00 \\
\hline Public safety as user of river transportation & 3.73 & 12.80 & 1 & 3 & 4.00 \\
\hline Accidents on site & 3.53 & 11.13 & 10 & 21 & 121.00 \\
\hline Accidents on river transport/river structure & 3.68 & 11.27 & 3 & 18 & 225.00 \\
\hline Loss or damage to machinery/structure & 3.47 & 10.83 & 12 & 22 & 100.00 \\
\hline Loss of human resources & 3.40 & 10.47 & 18 & 29 & 121.00 \\
\hline Total & & & & & 2376.50 \\
\hline
\end{tabular}


UNIMAS e-Journal of Civil Engineering: Volume 4, Issue 2

Spider plot of Risk Level versus Likelihood

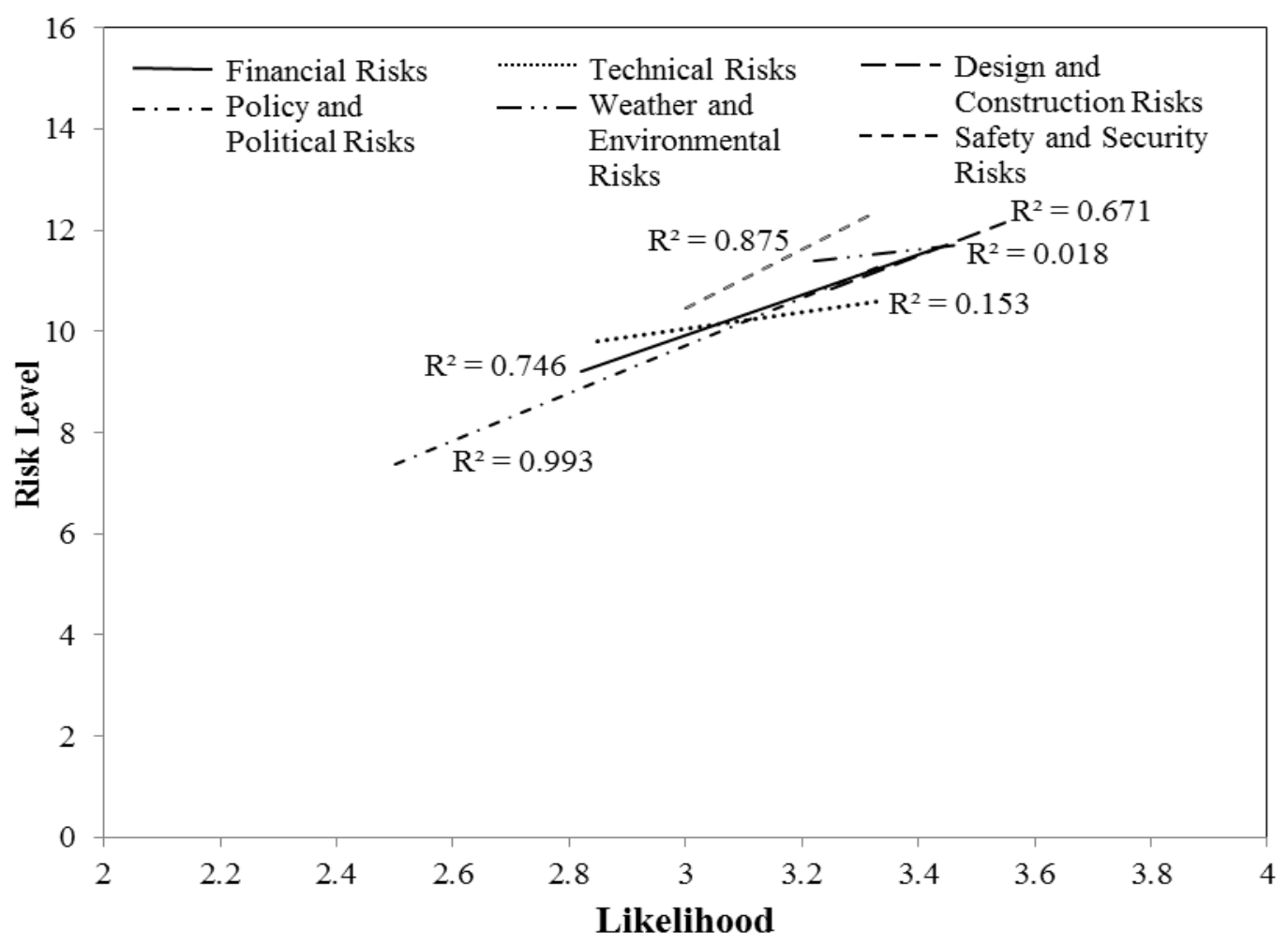

Figure 1 Sensitivity analysis of risk level versus likelihood

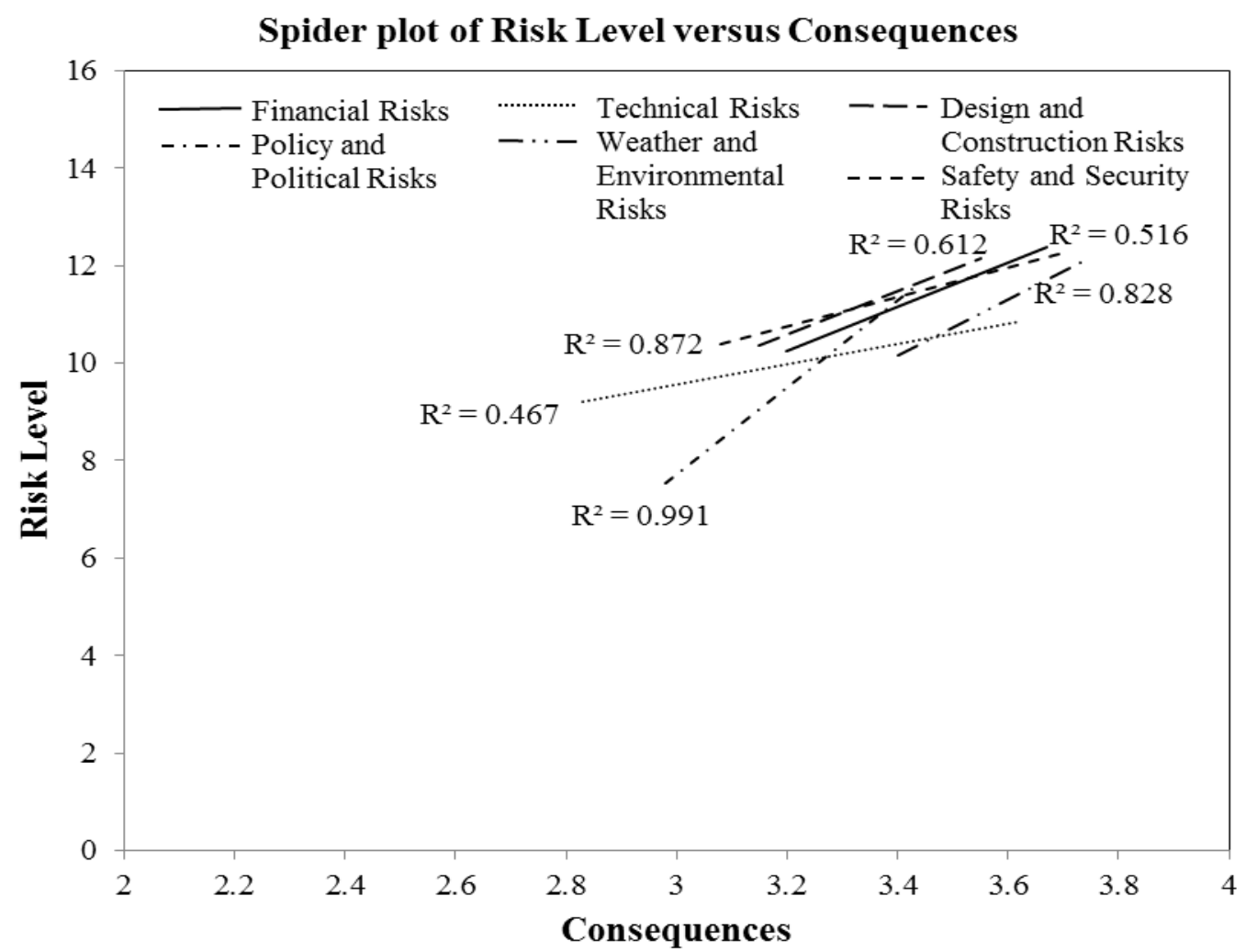

Figure 2 Sensitivity analysis of risk level versus consequences 


\section{DISCUSSIONS}

From the research, it is found the risk factors on financial issue have the highest rank and followed by public safety. It is due to the occurrence of the financial issue is far more likely than the public safety. The safety of the passenger can be increased by awareness campaign and provide enough safety features. However, the financial issue between parties is unpredictable. Besides, the price inflation is also uncontrollable by either party. Although the risk is known, the mitigation for the financial issue is still very critical and very dependent on the party. The material on the site provide by the contractor also might varies with the material used for construction. Furthermore, the construction fraud is too difficult to trace. Then the weather and environmental issue always come along with any building construction. The flooding, sedimentation and siltation of surrounding could affect the progress of the construction and even the function of the building later. Besides, sedimentation and siltation required high cost to alleviate. The lowest risk levels are referring to the policy and political issues. The risk factor of labour disputes and strikes might not record in any history. However, it is possible to occur especially during an economic downturn. The change in laws and regulations or government policies is rare too. It is the government is trying to develop this country with a consistency procedure to reduce confuses and also the complexity.

From the Spearman rank correlation analysis, it is found the coefficient for Spearman rank correlation between the likelihood and risk level is 0.750 whereby the critical value for Spearman rho at a confidence level of $95 \%$ is 0.2873 . Thus, the analysis proved that there is a correlation between the likelihood and risk level. Furthermore, the positive integer for Spearman rank correlation coefficient shows the likelihood and risk level form positive correlation. When the values of the likelihood and risk level plotted into scatter plot, the scatter pattern will show in positive gradient. It also shows that the increase of the likelihood tends to increase the risk level. However, the increase of risk level might affect by the consequence whereby the consequence of certain risk factors could be very low. Likewise, the Spearman rank correlation coefficient for consequences and risk level is 0.691 . Thus, the analysis proved that there is a correlation between consequence and risk level. Besides, the third variant issue might exist. The variable can be affected by the emotion of the respondents. Moreover, correlation does not imply causation which emphasises that correlation between two variables does not automatically imply that one causes the other. Therefore, the correlation between two variables is always done by ignoring a common cause.

Accordingly from the sensitivity analysis between the risk level and the likelihood of risk group, R2 stands for the proportion of variance in risk level accounted for by the likelihood. From Figure 1.0, the policy and political risk group show the highest R2 value which is 0.993 . It means that $99.3 \%$ of the variance in risk level is accounted for by the likelihoods of policy and political risk group. Likewise for the highest $\mathrm{R} 2$ value for Figure 2.0. The lowest $\mathrm{R}^{2}$ value of the relationship between likelihood and risk level is 0.018 for weather and environmental risk group. It is because the likelihood of the weather and environmental risk group does not drive the risk level while its consequences do. Then, the lowest $\mathrm{R}^{2}$ value of the relationship between consequence and risk level is 0.467 for the technical risk group. So, it can be concluded that the likelihood of this risk group is more accounted for the risk level instead of their likelihood.

\section{V.CONCLUSION}

Firstly, it is found that no proper documentation for risk identification for river transportation in Sarawak. However, there are some guidelines or suggestions on the locality, type and layouts for jetties and wharf construction. Some recommendations are made for further studies in the future. Firstly, the number of respondents shall be increased. And more experts shall be met to increase the reliability and validity of the questionnaires. Secondly, the face-to-face interview with respondent is required to minimise the chances of the respondent to rate on the middle point. Therefore, the validity for the collected data can be increased. Besides, the number of risk factors as well as risk group should be increased. Last but not least, the guidelines for risk management for river transportation could be developed as well as guidelines for risk mitigation.

\section{REFERENCES}

[1] Abd. Kader, Ab. Saman and Ahmad, Mohd. Zamani (2006). Utilisation of Inland Water Transport System in South East Asian Region - An Overview of the Prospect. Proceedings of first International Conference on Natural Resources Engineering and Technology. Retrieved May 19, 2011 from http://eprints.utm.my/3437/1/Utilisation_of_Inland_Water_Transport_System_in_South_East_A.pdf

[2] Gravetter, F., \& Forzano, L. B. (2006). Research method for the behavioural sciences (2nd ed.). California: Thomson Wadsworth.

[3] Jones, D. A. (1992). Nomenclature for hazard and risk assessment in the process industries (2nd ed.). Warwickshire: Antony Rowe Ltd.

[4] Mockett, I. D., \& Simm, J. D. (2002). Risk level in coastal and river engineering: A guidance framework for design. London: Thomas Telford Publishing

[5] Modarres, M., Kaminskiy, M. \& Krivtsov, V. (1999). Reliability engineering and risk analysis: A practical guide. New York: Marcel Dekker, Inc.

[6] Popoviciu, N., \& Baicu, F. (2009). A risk theory based on hyperbolic parallel curves and risk assessment in time. In S. Martorell, C. Guedes Soares \& J. Barnett (Eds.), Safety, Reliability and Risk Analysis: Theory, Methods and Application 2, 1027-1033. Leiden: CRC Press/Balkema

[7] PRLog Free Press Release. (2007, July 12). Undp-srb Enhance Sarawak River Transportation. Retrieved August 28, from http://www.prlog.org/10023726-undp-srb-enhance-sarawak-river-transportation.html

[8] Thorne, B. M. \& Geisen, J. M. (2003) Statistics for the behavioural sciences (4th ed.) Boston: McGraw Hill

[9] Zadeh, M. G. (2010). Risk management implementation in the Iraninan construction industry from contractors' perspective. (Master's Thesis). Retrieved November 21, 2010, from http://eprints.utm.my/11365/ 